\title{
Luis MORENO y Raúl JIMÉNEZ, Democracias Robotizadas. Escenarios Futuros en Estados Unidos y la Unión Europea, Madrid, Catarata, 2018. 158 páginas
}

\author{
Luis MORENO \& Raúl JIMÉNEZ, Democracias Robotizadas. \\ Escenarios Futuros en Estados Unidos y la Unión Europea, \\ Madrid, Catarata, 2018. 158 pp.
}

Carles Ramió Matas

Universitat Pompeu Fabra carles.ramio@upf.edu

\section{NOTA BIOGRÁFICA}

Catedrático de Ciencia Política y de la Administración.

\section{RESUMEN}

Recensión del libro Luis Moreno y Raúl Jiménez, Democracias Robotizadas. Escenarios Futuros en Estados Unidos y la Unión Europea, por Carles Ramió.

\begin{abstract}
Review of the book Luis Moreno y Raúl Jiménez, Democracias Robotizadas. Escenarios Futuros en Estados Unidos y la Unión Europea, by Carles Ramió.
\end{abstract}

Lo mejor de este libro de Luis Moreno y Raúl Jiménez es que da que pensar. En mi caso me ha dado que pensar tanto que me he preguntado al final se su lectura ¿puede la inteligencia artificial secuestrar a la democracia? Estas reflexiones no son del libro, pero las ha incentivado este libro. En este sentido hago una recensión muy personal ya que sinceramente nunca he sabido hacer recensiones. Lo que hay que hacer es leerse el libro y lo que le corresponde al comentador es intentar incentivar la lectura del mismo. En eso estamos.

La aplicación de la inteligencia artificial va a trasformar la gestión pública pero también afectará a la política y puede alterar las ideas que ahora asociamos a la democracia. Analicemos, por ejemplo, la noticia que apareció en los medios en 2017 sobre la implantación en Dubái de la inteligencia artificial: El verdadero gobernador de Dubái es un programa. Dubái ha creado recientemente una plataforma que combina big data con inteligencia artificial, para poner ese programa informático al servicio tanto de los gobernantes como de los ciudadanos. Se trata del verdadero gobernador de su ciudad. Además, la plataforma que aúna toda esa información (en forma de open data, o sea, disponible para todos los actores implicados en la vida de la ciudad), llamada Smart Decision Making Platform, ha sido también puesta al servicio de los ciudadanos: Un empresario que se plantea abrir un nuevo local en la ciudad y no sabe dónde. Una familia a la que se le ha quedado pequeña la casa y busca un nuevo lugar para sus planes vitales. Cualquiera puede acudir 
GAPP. Nueva Época - N. ${ }^{\circ}$ 20, noviembre 2018 - ISSN: 1989-8991 - DOI: 10.24965/gapp.v0i20.10571 - [Págs. 168-172] Número monográfico - Gobernanza y políticas de desarrollo urbano: teoría y práctica

Luis MORENO y Raúl JIMÉNEZ, Democracias Robotizadas. Escenarios Futuros en Estados Unidos y la Unión Europea, Madrid ..

Carles Ramió Matas

a esta plataforma inteligente, plantearle sus preferencias, y obtendrá una respuesta. Dubái tiene como guía la felicidad de los ciudadanos, y para ello ha adoptado varias tecnologías. Entre ellas, ha engarzado la tecnología móvil en la misma gestión pública. Es lo que llaman $m$-Government. Tiene una aplicación llamada Smart Majlis. Majlis es el nombre de las asambleas en las que la comunidad decide qué hacer. Con la aplicación cualquier ciudadano puede sacar una foto de algún servicio que le gusta, enviársela al gobierno de la ciudad, y explicar las razones por las que cree que debería adoptarse. Los funcionarios tienen que responder en dos semanas. Si tras estudiarse se adopta el servicio, el ciudadano recibe una compensación. Desde que se gestiona la digitalización de la ciudad desde un punto de vista «holístico», este sistema ha permitido ahorrar cuatro dihrams (la moneda local) por cada dihram invertido en el desarrollo de este sistema. En total, en diez años Dubái (que tiene 17.000 empleados públicos), ha ahorrado el equivalente a casi 1.500 millones de euros.

Los elementos conceptuales e instrumentales a destacar de esta noticia tienen dos niveles, uno de gestión y otro político. Las ventajas técnicas sobre la dimensión de gestión se utilizan como una coartada para justificar sutil y subliminalmente lo que puede ser una perversidad política:

En la dimensión de gestión todo son ganancias tanto a nivel conceptual como a nivel instrumental: un sistema holístico, transparente, con rendición de cuentas, participativo y colaborativo, que aporta una gran eficacia en la gestión junto con una gran eficiencia mediante un espectacular ahorro para las arcas públicas. Todo absolutamente impecable. Es un buen ejemplo de como la inteligencia artificial puede contribuir a la mejora de la calidad institucional y a la mejora de la gestión de las administraciones públicas.

En la dimensión de la política implica la robotización de la misma: con la introducción de la inteligencia artificial se accede al argumento de una dimensión política tecnocrática, donde no gobiernan políticos sino la tecnología: El gobernador de Dubái es un programa. Además, se le imprime una lógica comunitaria, al ser un programa abierto (open data) y que, al facilitar y reclamar la colaboración ciudadana, está abierto a la inteligencia colectiva y le asignan el elemento simbólico tradicional de ser como una asamblea comunitaria. Desde un punto político este discurso tiene su enjundia ya que, en este caso, la inteligencia artificial es utilizada como un mecanismo para justificar, modernizar y blanquear un sistema político autocrático. Dubái, que realmente es una dictadura medieval, aparentemente se transforma en un sistema político tecnocrático y comunitario. Eso sí, inquietantemente parecido a Un Mundo Feliz de Huxley (1932). En este sentido, no sería nada extraño que las actuales dictaduras (por ejemplo, China) intentaran legitimarse mediante la inteligencia artificial como mecanismo para modernizar y consolidar sus modelos autocráticos. Por otro lado, algunas democracias débiles (por ejemplo, Rusia) podrían utilizar la inteligencia artificial como una excusa para imprimir una deriva más autoritaria.

Por tanto, hay que estar alerta en cómo se puede instrumentalizar de manera política la revolución de la inteligencia artificial. Esta posibilidad es alarmante si se tienen en cuenta tres elementos adicionales que actualmente ponen en riesgo a las democracias liberales de cara al futuro:

Por una parte, la constatación de una tecnificación de la política. Mair (2015) sostiene que la política ha perdido el control económico, que el sistema de partidos está en crisis ya que no puede ofrecer alternativas distintas a los ciudadanos. «Dicho brevemente, el mundo ya lo gobiernan los grandes monopolios (u oligopolios) tecnológicos, financieros o de distribución junto a la red de organismos y lobbies internacionales (BM, $\mathrm{FMI}$, OCDE, etc.). Las ideas directrices de cómo gestionar la economía y los asuntos sociales son aplicados sin rechistar por los bancos centrales y los gobiernos» (Moreno y Jiménez, 2018: 148). Además, se han arrebatado competencias clave a la política y a los partidos al crearse agencias reguladoras independientes de carácter tecnocrático que son las que tienen más capacidad de incidencia sobre los ciudadanos (política monetaria, energética, financiera, etc.). Mair (2015) llega a argumentar que ya no existe en Europa una democracia popular y de masas, sino que existe una democracia formal, administrativa, inercial y constitucional (Ramió, 2017: 105). La revolución de la inteligencia artificial podría ser el argumento final para tecnificar de manera casi definitiva la política y la democracia.

Los países democráticos están experimentando una evidente deriva política de carácter populista. Timbro, un think tank sueco, ha diseñado un índice de populismo autoritario sumando los apoyos electorales de extrema derecha y de extrema izquierda en los países democráticos (Timbro, 2016): Hungría está a la cabeza con el 66 por ciento, pero le siguen Grecia con el 57, Polonia con el 46, Italia con el 34 . El panorama es inquietante. No es descabellado pensar que las opciones populistas en el gobierno (Hungría es el ejemplo actual más inquietante) utilizaran la inteligencia artificial como mecanismo para blanquear y modernizar las derivas autoritarias de sus sistemas institucionales. 
GAPP. Nueva Época - N. 20, noviembre 2018 - ISSN: 1989-8991 - DOI: 10.24965/gapp.v0i20.10571 - [Págs. 168-172] Número monográfico - Gobernanza y políticas de desarrollo urbano: teoría y práctica

Luis MORENO y Raúl JIMÉNEZ, Democracias Robotizadas. Escenarios Futuros en Estados Unidos y la Unión Europea, Madrid ...

Carles Ramió Matas

Los países con democracias débiles están en una situación de desconcierto ya que, por una parte, perciben como las democracias consolidadas (Europa y EE.UU) están en crisis y sus sistemas de gobierno son cada vez más caóticos, contradictorios, lentos e ineficientes en un mundo cada vez más rápido y competitivo. Por otra parte, perciben cómo hay sistemas autocráticos que están demostrando una enorme capacidad de adaptación a los retos tecnológicos y económicos (por ejemplo, China y los Emiratos Árabes) y sus gobiernos responden con eficacia y rapidez a las diversas encrucijadas. Con la excusa del discurso tecnológico estas democracias débiles podrían optar por seguir, por ejemplo, el modelo de Dubái.

En definitiva, hay que estar alerta a estos elementos o relatos que pueden intentar propiciar el uso la inteligencia artificial para poner en jaque a los actuales sistemas democráticos. Casi todos los autores consideran que estamos ante una revolución tecnológica que transformará de manera radical la economía, las relaciones laborales, las relaciones sociales, etc. Es obvio que también podrá transformar de una manera radical a la política. Este impacto sobre la política puede ser una democracia más profunda, más colaborativa y deliberativa que aproveche la tecnología mediante sistemas de participación directa que puedan capturar la inteligencia colectiva. Con un poder político mucho más transparente, con mayor rendición de cuentas y más sujeto al escrutinio experto de la ciudadanía, etc. Pero, cuidado, porque también podría tener una deriva totalmente contraria y poner en duda los valores y la esencia del sistema democrático.

Existe una relación causal evidente entre revolución tecnológica y cambio de paradigma político, una evidencia empírica si se analiza el impacto de la sociedad de la información durante los últimos diez años. En primer lugar, esta revolución tecnológica ha cambiado el modelo económico capitalista tradicional. La economía está dominada por la infoeconomía (economía de la sociedad de la información). Los motores de la economía, las empresas con más capital e influencia pertenecen a la infoeconomía. Son empresas que operan con lógicas de cuasimonopolios (Mason, 2016) y que con el argumento disruptivo no respetan las convenciones económicas y legales: operan sin competencia real, apenas tributan fiscalmente, no respetan las reglas laborales más esenciales y quebrantan el principio de privacidad y confidencialidad de los datos personales de los ciudadanos (Keen, 2016). Es el regreso vanguardista del capitalismo salvaje. Moreno y Jiménez (2018: 151) hacen referencia a un modelo neofeudal en el que los nuevos señores feudales son los plutócratas (empresas y personas que acumulan la mayor parte del capital). Este cambio tecnológico y económico junto con el impacto de la globalización está manifestando un impacto brutal en las sociedades de los países más avanzados. El resultado es una mayor desigualdad social por la pérdida de empleos derivada de la implantación tecnológica, pero en especial, por una nueva organización laboral con una corona enorme de empleados inestables y con muy bajos salarios y un diminuto núcleo con empleados estables y bien retribuidos (Moreno y Jiménez, 2018; Mason, 2016). Y este núcleo se nutre en buena parte, hasta ahora, de los empleados públicos. Pero en el futuro esto ya no será así. Las sociedades occidentales están atemorizadas y crispadas y exigen respuestas al poder político (al sistema de partidos y a la democracia popular). Pero como argumenta Mair (2015) la política es impotente, no tiene capacidad de incidencia en la economía, no posee respuestas satisfactorias a los ciudadanos. Y los ciudadanos crispados optan por opciones políticas populistas y demagógicas que coquetean con una visión política de carácter autocrático. Este proceso es el resultado del impacto de la revolución tecnológica de la sociedad de la información. Y ahora se acerca una revolución tecnológica todavía más radical de la mano de la robótica y de la inteligencia artificial y que puede reproducir con total exactitud, pero de una manera mucho más radical, esta concatenación de impactos entre la tecnología, la economía, la sociedad, la política y el modelo político. Las empresas tecnológicas van a acumular todavía más poder, se van a perder muchos más puestos de trabajo que hasta ahora, los desequilibrios salariales pueden ser mucho más agudos. La sociedad va a estar todavía más temerosa, crispada e incluso histérica. La política convencional va a continuar sin tener ninguna respuesta. Y, finalmente, las opciones políticas demagógicas podrían utilizar como excusa y argumento la promoción de un gobierno tecnocrático y autocrático de la mano de la inteligencia artificial. Es alarmante constatar cómo se está produciendo una brecha generacional en la percepción de la democracia. Las personas mayores apoyan mayoritariamente al sistema democrático pero los jóvenes son mucho más receptivos a alternativas de corte autoritario (en EE.UU y en el Reino Unido) (Moreno y Jiménez, 2018; Castells, 2017). Por tanto, el binomio o alianza entre inteligencia artificial y sistema político autocrático no es en absoluto absurdo. La literatura en ciencia ficción desde Julio Verne ha adivinado algunas innovaciones tecnológicas y otras no. Pero hay una inquietante casi unanimidad en esta literatura: muestran un sistema político tecnocrático, eficiente, neutral, paternalista, etc. pero autocrático. 
GAPP. Nueva Época - N. ${ }^{\circ}$ 20, noviembre 2018 - ISSN: 1989-8991 - DOI: 10.24965/gapp.v0i20.10571 - [Págs. 168-172] Número monográfico - Gobernanza y políticas de desarrollo urbano: teoría y práctica

Luis MORENO y Raúl JIMÉNEZ, Democracias Robotizadas. Escenarios Futuros en Estados Unidos y la Unión Europea, Madrid ...

Carles Ramió Matas

Por el momento ya tenemos algunos indicios de como la inteligencia artificial nos puede conducir, si no se pone atención, a un neofeudalismo (Moreno y Jiménez, 2018: 124-125): «¿Qué papel jugarán en las democracias robotizadas los expertos en inteligencia artificial? (...) El caso de Cambridge Analytica, destapado a principios de 2018, es revelador de las malas prácticas ejercidas por expertos especializados al servicio del poder (...) Esta empresa era un auténtico arsenal de armas en una guerra cultural dentro de la sociedad norteamericana auspiciada por la ultraderecha (...) Estamos, por ende, ante la génesis de un escenario de neofeudalismo en el que unos pocos podrían controlar los recursos de los nuevos siervos».

Pero la inteligencia artificial es también una gran oportunidad para resolver los problemas globales en el mundo. Los expertos consideran (Rodríguez, 2018: 247 y 248) que puede contribuir a conseguir el hambre cero aumentando la productividad en la agricultura; eliminar la pobreza (elaborando un mapa de pobreza y estableciendo análisis de datos de valor predictivo); establecer mejoras significativas en la sanidad y el bienestar gracias al análisis de enormes cantidades de datos sobre la asistencia sanitaria; mejorar la calidad de la educación gracias a nuevos sistemas de aprendizaje personalizado; igualdad de género detectando las desigualdades e impulsando el empleo equilibrado entre ambos sexos; agua limpia y eliminación de residuos; energía limpia y accesible; ciudades y comunidades sostenibles; consumo y producción responsables; mayor control de la pesca y de la caza ilegal; mengua muy significativa de la evasión fiscal; y disminución de la corrupción institucional. En este sentido, existe casi unanimidad en la literatura especializada en que la inteligencia artificial pude generar unos enormes beneficios sociales, económicos y de sostenibilidad a corto plazo y a nivel laboral también, pero a más largo plazo (menos horas de trabajo y renta universal mínima) (Schwad, 2016, Boden, 2017; Tamames, 2018; Rodriguez, 2018). Solucionar estos grandes retos mundiales puede ser una manera muy eficaz para lograr un mayor desarrollo y legitimidad de los sistemas democráticos. Bienestar social y democracia es un binomio que suele generar una retroalimentación mutuamente beneficiosa.

Vuelvo al libro de Moreno y Jiménez que he citado profusamente hasta ahora. Se trata de un ensayo y tengo que confesar que soy un fan del género de los ensayos, un estilo que valora mucho la academia anglosajona y que lentamente se va implantando en España. Soy de los convencidos que el conocimiento científico puede avanzar más por las carreteras de los ensayos que por las autopistas de los artículos académicos indexados y ubicados en los primeros cuartiles. El ensayo representa libertad, desinhibición, creatividad y, usualmente, una vocación de frontera entre distintas especialidades científicas. Los ensayos pueden ser la punta de lanza para abrir nuevos caminos científicos y, por si fuera poco, suelen tener una vocación divulgativa que permite un acceso más democrático y multidisciplinar. Un buen ensayo siempre es una aportación de madurez académica e intelectual. El autor o autores de un ensayo suelen ser reconocidos especialistas en una materia que tienen la capacidad y la osadía de concatenarla con otros enfoques disciplinarios o por, por ejemplo, con novedades como la tecnología que puede transformar nuestras realidades. Todos estos ingredientes están presentes en este libro con el añadido que se trata de un osado y original debate entre un sociólogo/politólogo con un cosmólogo/astrofísico. Se trata de mirar a las estrellas del futuro con los pies en la sociedad y en el sistema institucional para analizar el impacto de la robótica en la política y en la sociedad del bienestar sea ésta continental (Estado del Bienestar) o americana (el supuesto mercado del bienestar). Los títulos de los apartados son muy sugerentes, a modo de ejemplo: un mundo de algoritmos (en los próximos años los especialistas en gestión pública vamos a tener que debatir sobre los algoritmos que van a conformar la inteligencia de las políticas y de los servicios públicos), capitalismo de casino, consumismo conspicuo, asalariados pobres y ciudadanos precarios, señores y plebeyos de nuevo cuño, la gobernanza privada de la cosa pública (otro gran tema de la gestión pública), convivencia entre robots y humanos, etc. El autor que forma parte de nuestra tribu académica es Luís Moreno, sociólogo y politólogo especializado en el Estado de Bienestar que es el académico español más citado a nivel internacional en ciencias sociales (hoy 13.200 citas en el Google Scholar). Se trata sencillamente de un lujo académico nacional que, para los que le conocemos, tiene siempre una actitud amable, cercana y modesta solo al alcance de los grandes científicos. Para finalizar me da la impresión que no sería una recensión completa si no incluyera alguna crítica. En este caso no se trata de críticas específicas a la obra que se presenta sino de debilidades vinculadas al género del ensayo. Son la cruz de este género: reiteraciones argumentales, la tendencia de arrimar el ascua a la sardina académica que cada uno cocina (Estado del Bienestar en el caso de Luis Moreno), dejar cabos sueltos con argumentos esquematizados pero pendientes de colorear, etc. Bienvenidos sean estas debilidades si introducen a los profanos en la materia y alientan a los investigadores más formales a abrir nuevos espacios de investigación. Para mí un ensayista es como Santa Teresa, funda un convento de nueva planta para que los monjes o monjas siembren nuevos huertos intelectuales. 
GAPP. Nueva Época - N. 20, noviembre 2018 - ISSN: 1989-8991 - DOI: 10.24965/gapp.v0i20.10571 - [Págs. 168-172] Número monográfico - Gobernanza y políticas de desarrollo urbano: teoría y práctica

Luis MORENO y Raúl JIMÉNEZ, Democracias Robotizadas. Escenarios Futuros en Estados Unidos y la Unión Europea, Madrid ...

Carles Ramió Matas

\section{BIBLIOGRAFÍA}

BODEN, M. (2017): Inteligencia Artificial. Madrid: Taurus.

CASTELLS, M. (2017): Ruptura: la Crisis de la Democracia Liberal. Madrid: Alianza.

HUXLEY, A. (1932): Un Mundo Feliz. Edición más actual en español, 2013 (Jesús Isaías Gómez López). Madrid: Cátedra.

KEEN, A. (2016): Internet no es la respuesta. Barcelona: Catedral.

MAIR, P. (2015): Gobernando el Vacío. La banalización de la Democracia Actual. Madrid: Alianza Editorial.

MASON, P. (2016): Postcapitalismo. Hacia un nuevo futuro. Barcelona: Paidós.

RAMIÓ, C. (2017): La Administración Pública del Futuro (Horizonte 2050). Instituciones, Política, Mercado y Sociedad de la Innovación. Madrid: Tecnos.

RODRíGUEZ, P. (2018): Inteligencia Artificial. Cómo Cambiará el Mundo (y tu Vida). Barcelona: Deusto.

SCHWAD, K. (2016): La Cuarta Revolución Industrial. Barcelona: Debate.

TAMAMES, R. (2018): ¿Qué Robot se ha Llevado mi Queso? Barcelona: Alienta Editorial.

TIMBRO (2016): Timbro Authoritarian Populism Index 2016. En línea: http://timbro.se/en/rapporter/timbro-authoritarianpopulism-index-2016-0. 